\title{
Microsurgical ligation for incompletely coiled or recurrent intracranial aneurysms: a 17-year single-center experience
}

Jun Wu ${ }^{1,2,3,4}$, Xianzeng Tong ${ }^{5}$, Qingyuan Liu ${ }^{1,2,3,4}$, Yong Cao ${ }^{1,2,3,4}$, Yuanli Zhao ${ }^{1,2,3,4}$ and Shuo Wang ${ }^{1,2,3,4^{*}}$

\begin{abstract}
Background: In this retrospective single-center study, we presented our experience in the microsurgical management of incompletely coiled or recurrent aneurysms after initial endovascular coiling.

Methods: During a 17-year period, 48 patients underwent microsurgical clipping of incompletely coiled or recurrent aneurysms after coiling (Gurian group B). The clinical data, surgical technique, and postoperative outcome were recorded and analyzed.

Results: Before coiling, 42 patients (87.5\%) experienced aneurysm rupture. Most of the aneurysms (46/48, 96\%) were located in the anterior circulation. After coiling, 6 patients had incompletely coiled aneurysms and 42 patients had recurrent aneurysms, with a mean time of 20.2 months from coiling to recurrence. Coil extrusion occurred in none of the incompletely coiled aneurysms and 71\% (30/42) of the recurrent aneurysms. Clipping techniques are direct microsurgical clipping without coil removal in 16 patients, partial coil removal in 14 patients, and total coil removal in 18 patients. Postoperative and follow-up angiography revealed complete occlusion of the aneurysms in all patients. No patient died during postoperative follow-up period (mean, 78.9 months; range, 10-190 months). Good outcomes (GOS of 4 or 5) were achieved in $87.5 \%$ (42/48) of the patients at the final follow-up.

Conclusions: Microsurgical clipping is effective for incompletely coiled or recurrent aneurysms after initial coiling. For recurrent aneurysms that have coils in the neck, have no adequate neck for clipping, or cause mass effects on surrounding structures, partial or total removal of coiled mass can facilitate surgical clipping and lead to successful obliteration of the aneurysms.
\end{abstract}

Keywords: Coiled aneurysms, Recurrent aneurysms, Endovascular coiling, Microsurgical clipping

\section{Background}

Incompletely coiled or recurrent aneurysms after embolization have been reported since the use of coil in aneurysm treatment. The reported rate of aneurysm recurrence after initial endovascular therapy was between 3.6 to $40 \%$ [5, 8, 21, 32, 35]. The International Subarachnoid Aneurysm Trial (ISAT) reported a combined rate of $34 \%$ for aneurysm incomplete obliteration and recurrence after initial endovascular coiling [21]. Subsequent follow-up data in ISAT showed that $191(17.4 \%)$ out of 1096 patients

\footnotetext{
* Correspondence: captain9858@vip.sina.com

'Department of Neurosurgery, Beijing Tiantan Hospital, Capital Medical University, Beijing 100050, China

${ }^{2}$ China National Clinical Research Center for Neurological Diseases, Beijing, China

Full list of author information is available at the end of the article
}

required retreatment for incomplete occlusion or recurrence and 103 patients (54\%) required neurosurgical management [5]. In the Cerebral Aneurysm Rerupture After Treatment (CARAT) study, the annual retreatment rates of coiled aneurysms were $13.3 \%, 4.5 \%$, and $1.1 \%$ respectively during the first, second, and subsequent years [17]. Incompletely obliterated or recurrent aneurysms were more likely to rupture or cause mass effect symptoms than the completely obliterated aneurysms [6-9, 17, 18, 27].

Microsurgical ligation is a treatment strategy for incompletely coiled or recurrent intracranial aneurysm. Surgical management of these aneurysms is challenging. In some cases, the surgical clipping might be the optimal choice. In this study, we retrospectively analyzed our experience of

(C) The Author(s). 2019 Open Access This article is distributed under the terms of the Creative Commons Attribution 4.0 International License (http://creativecommons.org/licenses/by/4.0/), which permits unrestricted use, distribution, and reproduction in any medium, provided you give appropriate credit to the original author(s) and the source, provide a link to the Creative Commons license, and indicate if changes were made. The Creative Commons Public Domain Dedication waiver (http://creativecommons.org/publicdomain/zero/1.0/) applies to the data made available in this article, unless otherwise stated. 
the surgical clipping for incompletely coiled or recurrent aneurysms in our center.

\section{Methods}

\section{Patients inclusion}

The patients that underwent microsurgical ligation of incompletely coiled or recurrent aneurysms after endovascular coiling were searched from the Beijing Tiantan Hospital Cerebral Aneurysm Surgical Treatment database from January 2000 to January 2017. Only the patients with incomplete obliteration or recurrence after coiling (Gurian group B) who received subsequent open surgery were included in this study. Patients were excluded with a failed endovascular treatment with no embolic coils used (Gurian group A) or surgery for the complications related to endovascular therapy (Gurian group C) [14].

\section{Recurrence and therapeutic decision}

After initial endovascular coiling, the patients were followed-up to evaluate the efficacy of initial coiling. The follow-up imaging including magnetic resonance angiography (MRA) and digital subtraction angiography (DSA). Recurrence latency was defined as the time interval between the initial endovascular coiling and the time when the follow-up image clinically showed recurrence.

For incompletely obliterated or recurrent aneurysms after coiling, the treatment strategy was made by a multidisciplinary team including vascular neurosurgeons and interventional neuroradiologists.

\section{Surgical technique}

All surgical procedures were performed by either of two experienced vascular neurosurgeons in our center. Coil removal was indicated when the coils protruded into aneurysm neck or parental arteries that hamper satisfactory surgical clipping. Coil removal was also indicated to avoid stenosis of the parental arteries when there was no adequate neck for clipping. For the recurrent aneurysms that caused mass effects, the coils need to be partially or totally removed. Considering that large or giant aneurysms (size $\geq 10 \mathrm{~mm}$ ) may cause potential mass effects, we also performed partial or total removal of the coils. For the aneurysms that were small-sized but had adequate neck for clipping (without coil migration into the neck), direct clipping without coil removal was performed. Direct clipping was also used for the aneurysms that were difficult to dissect but had adequate neck for clipping (without coil migration into the neck). None of our patients underwent bypass surgery, parent artery occlusion, or wrapping. Microvascular Doppler ultrasonography or indocyanine green video angiography was used during surgery to verify the exclusion of aneurysms and preservation of branches.

\section{Follow-up and outcome evaluation}

All patients in this series underwent postoperative angiography 3 to 7 days after surgical clipping to document complete obliteration of the aneurysms. Follow-up DSA or MRA was performed at 6 months after surgery and annual. Neurological assessments were performed preoperatively, postoperatively, and during the follow-up period. The Glasgow Outcome Scale (GOS) score was used to define clinical outcomes. Good outcomes were defined as a GOS of 4 or 5 at the final follow-up evaluation and poor outcomes were defined as a final GOS of less than 4 . The changes in GOS score from the preoperative to final follow-up evaluation were also documented.

\section{Data analysis}

Statistical analyses were performed with the Statistical Package for the Social Sciences software (version 20.0; SPSS, Inc., Chicago, Illinois). Patient demographics (age at surgery, sex, presentation), aneurysm characteristics (side, size, location, initial result after coiling, recurrent latency, and DSA aspect of the recurrence), intraoperative and postoperative results (surgical technique and follow-up data), and neurological status (GOS) were entered into a spreadsheet. All data were summarized using descriptive statistics for continuous variables (mean \pm standard deviation, minimum and maximum) and categorical variables (count and percentage).

\section{Results}

Initial patient presentation and aneurysm characteristics

Ultimately, during the 17 -year period, 48 patients with 48 aneurysms underwent microsurgical management of incompletely obliterated or recurrent aneurysms previously treated by coiling. The mean follow-up period was 78.9 months (range, 10 months to 190 months). The medical records, radiographic studies, operative results, and follow-up data were reviewed retrospectively (Tables 1 and 2). We presented in this article six illustrations (patient 1, 2, 5, 7, 28 and 47; Figs. 1, 2, 3, 4, 5, 6, 7, 8, and 9).

As illustrated in Table 1, this series included 22 female and 26 male patients with a mean age of 46.5 years (range, 3 to 68 years) at the time of surgery. Forty-two patients (87.5\%) had a history of aneurysmal subarachnoid hemorrhage (SAH), with Hunt and Hess grade I in 11 patients, grade II in 19 patients, grade III in 10 patients, and grade IV in 2 patients. The aneurysms in the other 6 patients were incidentally found after head trauma or chronic headaches. Eight aneurysms were classified as giant (at least $25 \mathrm{~mm}$ ), 23 were classified as large $(10-24 \mathrm{~mm})$, and 17 were classified as small (less than $10 \mathrm{~mm}$ ). Forty-six aneurysms were located in the anterior circulation and 2 were located in the posterior circulation. 
Table 1 Preoperative data of patient characteristics

\begin{tabular}{|c|c|c|c|c|c|c|c|c|c|}
\hline Patient no. & Age $(y r) / s e x$ & Presentation & $\mathrm{HH}$ & Aneurysm location & Side & Size $(m m)$ & Coiling result & Recurrence & Latency \\
\hline 1 & $47 / F$ & $\mathrm{SAH}$ & 2 & MCA & $\mathrm{R}$ & 25 & Complete occlusion & Angiographic & 36 \\
\hline 2 & $12 / \mathrm{M}$ & $\mathrm{SAH}$ & 2 & A1 ACA & L & 15 & Complete occlusion & Angiographic & 3 \\
\hline 3 & $38 / \mathrm{M}$ & $\mathrm{SAH}$ & 2 & PComA & $\mathrm{R}$ & 12 & Incomplete occlusion & - & - \\
\hline 4 & $64 / F$ & $\mathrm{SAH}$ & 3 & PComA & L & 17 & Complete occlusion & $\mathrm{SAH}$ & 18 \\
\hline 5 & $3 / M$ & Hemiplegia & 0 & MCA & L & 26 & Complete occlusion & Angiographic & 11 \\
\hline 6 & $64 / M$ & $\mathrm{SAH}$ & 2 & PComA & $\mathrm{R}$ & 12 & Slight neck remnant & Mass effect & 21 \\
\hline 7 & $33 / \mathrm{M}$ & $\mathrm{SAH}$ & 2 & MCA & L & 50 & Complete occlusion & Mass effect & 15 \\
\hline 8 & $16 / \mathrm{M}$ & $\mathrm{SAH}$ & 3 & P2 PCA & L & 40 & Complete occlusion & Mass effect & 28 \\
\hline 9 & $42 / F$ & $\mathrm{SAH}$ & 2 & PComA & $\mathrm{R}$ & 10 & Complete occlusion & Angiographic & 10 \\
\hline 10 & $45 / F$ & Headache & 0 & ICA-OA & L & 20 & Complete occlusion & Angiographic & 30 \\
\hline 11 & $46 / F$ & $\mathrm{SAH}$ & 2 & MCA & $\mathrm{R}$ & 7 & Slight neck remnant & Angiographic & 18 \\
\hline 12 & $63 / F$ & $\mathrm{SAH}$ & 3 & PComA & L & 6 & Complete occlusion & Angiographic & 38 \\
\hline 13 & $49 / M$ & $\mathrm{SAH}$ & 2 & AComA & M & 30 & Incomplete occlusion & - & - \\
\hline 14 & $46 / M$ & $\mathrm{SAH}$ & 2 & AComA & M & 25 & Complete occlusion & Mass effect & 13 \\
\hline 15 & $34 / F$ & Trauma & 0 & PComA & L & 6 & Slight neck remnant & Angiographic & 15 \\
\hline 16 & $55 / F$ & $\mathrm{SAH}$ & 2 & PComA & L & 10 & Complete occlusion & Angiographic & 16 \\
\hline 17 & $38 / \mathrm{M}$ & $\mathrm{SAH}$ & 1 & PComA & $\mathrm{R}$ & 28 & Complete occlusion & Angiographic & 20 \\
\hline 18 & $28 / F$ & $\mathrm{SAH}$ & 1 & A2 ACA & $\mathrm{R}$ & 6 & Slight neck remnant & Angiographic & 12 \\
\hline 19 & $68 / F$ & $\mathrm{SAH}$ & 2 & PComA & $\mathrm{R}$ & 8 & Complete occlusion & Angiographic & 5 \\
\hline 20 & $60 / M$ & $\mathrm{SAH}$ & 1 & A3 ACA & $\mathrm{R}$ & 11 & Complete occlusion & $\mathrm{SAH}$ & 30 \\
\hline 21 & $47 / F$ & Headache & 0 & ICA-OA & L & 20 & Complete occlusion & Mass effect & 12 \\
\hline 22 & $53 / \mathrm{M}$ & $\mathrm{SAH}$ & 1 & AComA & M & 5 & Slight neck remnant & Angiographic & 16 \\
\hline 23 & $68 / F$ & $\mathrm{SAH}$ & 4 & MCA & $\mathrm{R}$ & 8 & Complete occlusion & $\mathrm{SAH}$ & 10 \\
\hline 24 & $42 / \mathrm{M}$ & $\mathrm{SAH}$ & 4 & PComA & L & 25 & Complete occlusion & Angiographic & 7 \\
\hline 25 & $47 / F$ & $\mathrm{SAH}$ & 3 & AComA & M & 16 & Complete occlusion & Angiographic & 11 \\
\hline 26 & $42 / M$ & $\mathrm{SAH}$ & 3 & AComA & M & 12 & Incomplete occlusion & - & - \\
\hline 27 & $20 / \mathrm{M}$ & Trauma & 0 & PComA & L & 15 & Complete occlusion & Mass effect & 28 \\
\hline 28 & $16 / F$ & $\mathrm{SAH}$ & 1 & PComA & $\mathrm{R}$ & 8 & Complete occlusion & Angiographic & 12 \\
\hline 29 & $51 / \mathrm{M}$ & $\mathrm{SAH}$ & 3 & PComA & $\mathrm{R}$ & 5 & Slight neck remnant & Angiographic & 53 \\
\hline 30 & $56 / F$ & $\mathrm{SAH}$ & 3 & AComA & M & 12 & Complete occlusion & Mass effect & 36 \\
\hline 31 & $57 / F$ & $\mathrm{SAH}$ & 2 & MCA & L & 10 & Incomplete occlusion & - & - \\
\hline 32 & $43 / \mathrm{M}$ & $\mathrm{SAH}$ & 2 & AComA & M & 8 & Complete occlusion & Angiographic & 36 \\
\hline 33 & $54 / M$ & $\mathrm{SAH}$ & 2 & AComA & M & 12 & Complete occlusion & Mass effect & 18 \\
\hline 34 & $52 / \mathrm{M}$ & $\mathrm{SAH}$ & 1 & MCA & $\mathrm{R}$ & 18 & Incomplete occlusion & - & - \\
\hline 35 & $48 / M$ & $\mathrm{SAH}$ & 1 & A3 ACA & $\mathrm{R}$ & 9 & Complete occlusion & $\mathrm{SAH}$ & 4 \\
\hline 36 & $49 / M$ & $\mathrm{SAH}$ & 1 & AComA & M & 5 & Incomplete occlusion & - & - \\
\hline 37 & $37 / M$ & $\mathrm{SAH}$ & 2 & MCA & $\mathrm{R}$ & 8 & Complete occlusion & Angiographic & 60 \\
\hline 38 & $45 / M$ & $\mathrm{SAH}$ & 2 & P2 PCA & $\mathrm{R}$ & 10 & Slight neck remnant & Angiographic & 12 \\
\hline 39 & $47 / F$ & $\mathrm{SAH}$ & 2 & PComA & $\mathrm{R}$ & 6 & Complete occlusion & Angiographic & 36 \\
\hline 40 & $55 / F$ & $\mathrm{SAH}$ & 1 & PComA & $\mathrm{R}$ & 7 & Slight neck remnant & Angiographic & 6 \\
\hline 41 & $45 / M$ & $\mathrm{SAH}$ & 2 & AComA & M & 14 & Complete occlusion & Angiographic & 9 \\
\hline 42 & $55 / \mathrm{M}$ & $\mathrm{SAH}$ & 1 & A2 ACA & $\mathrm{R}$ & 10 & Complete occlusion & Angiographic & 12 \\
\hline 43 & $63 / F$ & $\mathrm{SAH}$ & 3 & PComA & $\mathrm{R}$ & 13 & Complete occlusion & Angiographic & 20 \\
\hline 44 & $51 / M$ & $\mathrm{SAH}$ & 3 & AComA & M & 8 & Complete occlusion & Angiographic & 12 \\
\hline
\end{tabular}


Table 1 Preoperative data of patient characteristics (Continued)

\begin{tabular}{llllllllll}
\hline Patient no. & Age $(\mathrm{yr}) / \mathrm{sex}$ & Presentation & HH & Aneurysm location & Side & Size $(\mathrm{mm})$ & Coiling result & Recurrence & Latency \\
\hline 45 & 59/F & SAH & 1 & PComA & L & 17 & Complete occlusion & Angiographic & 75 \\
46 & 61/F & SAH & 3 & PComA & R & 12 & Complete occlusion & Angiographic & 12 \\
47 & 62/F & Headache & 0 & AComA & M & 15 & Complete occlusion & Mass effect & 9 \\
48 & 57/M & SAH & 2 & A1 ACA & R & 6 & Complete occlusion & Angiographic & 5 \\
\hline
\end{tabular}

yr years, $F$ female, $M$ male, $S A H$ subarachnoid hemorrhage, $H-H$ Hunt and Hess grade, $M C A$ middle cerebral artery, $A C A$ anterior cerebral artery, $P C o m A$ posterior communicating artery, $P C A$ posterior cerebral artery, ICA-OA internal carotid artery-ophthalmic artery, $A C o m A$ anterior communicating artery, $R$ right, $L$ left, $M$ middle, Latency time interval from initial coiling to recurrence

\section{Endovascular management}

The initial endovascular coiling was performed without adjuvant techniques (balloon-assisted or stent-assisted coiling). After initial coiling, complete obliteration was achieved in 34 patients, slight neck remnant (90-99\% occlusion) in 8 patients, and incomplete obliteration $(<90 \%$ occlusion) in 6 patients (Table 1). Routine follow-up cerebral angiography was performed for those 42 patients with completely or nearly completely obliterated aneurysms after initial embolization. All the 6 patients with initially incompletely obliterated aneurysms were referred for microsurgical management within 1 month after initial endovascular coiling and no patients experienced rebleeding during this time interval. Four patients presented with rebleeding at the time of 4 months, 10 months, 18 months, and 30 months respectively after initial coiling (Table 1 ). There were 29 patients without symptomatic deterioration after coiling showed significant angiographic recurrence on follow-up angiography. Nine patients experienced symptomatic mass effects, including 4 AComA aneurysms causing visual deterioration, 2 PComA aneurysms causing nerve III palsy, 1 OphA aneurysm with visual deterioration, 1 PCA aneurysm with mild hemiplegia, and $1 \mathrm{MCA}$ aneurysm with secondary epilepsy. Cerebral angiography of these aneurysms of with mass effects or rebleeding also showed significant aneurysm recurrence. The mean time from initial coiling to recurrence (recurrent latency) for the 42 patients was 20.2 months (range, 3 months to 75 months, Table 1). The hemorrhage rate after aneurysm coiling for our series was $8.3 \%$ ( 4 of 48 patients).

\section{Microsurgical management}

One patient (patient 5) underwent microsurgical clipping 4 months after recoiling. Other patients underwent microsurgical clipping within 2 months after the diagnosis of incompletely coiled or recurrent aneurysms. During surgery, most of the coiled aneurysms had a thin, translucent, and fragile wall (Figs. 3, 5, and 9). Of the 6 patients with initially incompletely coiled aneurysms, due to short time interval from coiling to surgery, no one was observed with coil compaction or coil extrusion through the aneurysm wall into the subarachnoid space (Table 2). Of the 42 recurrent coiled aneurysms, 71\% (30/42) were observed with coils extrusion into the subarachnoid space (Figs. 6 and 9) and 29\% (12/42) had coil compaction (Table 2, Figs. 3 and 5). Partial or total removal of coils was considered to facilitate microsurgical clipping when the coiled aneurysms caused mass effects, the coils protruded into the aneurysm neck, or no adequate neck remnant for clipping. As listed in Table 2, of all the 48 patients, direct surgical clipping without coils removal was accomplished in 16 patients (33.3\%; Fig. 7). Surgical clipping with partial coil removal was achieved in 14 patients (29.2\%). Surgical clipping with total removal of coils was performed in 18 patients (37.5\%; Figs. 1, 3, 5, 6, and 7). Bypass surgery, trapping, or wrapping was not performed in any of our patients.

\section{Follow-up}

Postoperative angiography revealed that all the previously coiled aneurysms in our series were completely obliterated after microsurgical clipping. No patient died during the postoperative follow-up period. Two patient experienced transient neurological deficit that resolved completely at 3 and 5 months respectively after surgery. Postoperative hydrocephalus occurred in 3 patients, of which 2 patients received V-P shunt and the other one was relatively stable by observation. At the final follow-up, good outcomes (GOS of 4 or 5 ) were achieved in $87.5 \%(42 / 48)$ of the patients. Five patients had a GOS of 3 and one had a GOS of 2. Compared with the preoperative GOS scores, the patient neurological outcome (GOS) at the final evaluation was improved or unchanged in $89.6 \%$ and worse in $10.4 \%$.

\section{Discussion}

Endovascular treatment of intracranial aneurysms has developed rapidly since its first introduction in 1974 [30]. Endovascular coiling has become a routine technique for intracranial aneurysms since the development of Guglielmi detachable coils in the 1990s [13]. With the increasing number of patients undergoing aneurysm endovascular coiling, the population of patients with incompletely coiled or recurrent aneurysms continues to increase. Aneurysm recurrence after initial endovascular therapy has been documented to occur at a rate of 3.6 to $40 \%[5,7,17,23,25]$. However, there are no established guidelines regarding the treatment modality for these previously coiled aneurysms. Treatment options include repeat endovascular treatment, microsurgical clipping, 
Table 2 Microsurgical results and follow-up data

\begin{tabular}{|c|c|c|c|c|c|c|c|c|c|}
\hline \multirow{2}{*}{$\begin{array}{l}\text { Patient } \\
\text { no. }\end{array}$} & \multirow{2}{*}{$\begin{array}{l}\text { Age } \\
(y r) / \text { sex }\end{array}$} & \multirow{2}{*}{$\begin{array}{l}\text { Aneurysm } \\
\text { location }\end{array}$} & \multirow{2}{*}{$\begin{array}{l}\text { Coil compaction } \\
\text { or extrusion }\end{array}$} & \multirow[t]{2}{*}{ Microsurgery } & \multirow{2}{*}{$\begin{array}{l}\text { Aneurysm } \\
\text { occlusion }\end{array}$} & \multicolumn{2}{|l|}{ GOS } & \multirow[t]{2}{*}{ Outcome } & \multirow{2}{*}{$\begin{array}{l}\text { Follow- } \\
\text { up (m) }\end{array}$} \\
\hline & & & & & & Preop & Final & & \\
\hline 1 & $47 / F$ & MCA & Extrusion & Clip + TCR & Complete & 5 & 5 & Unchanged & 190 \\
\hline 2 & $12 / \mathrm{M}$ & A1 ACA & Compaction & Clip + TCR & Complete & 5 & 5 & Unchanged & 182 \\
\hline 3 & $38 / \mathrm{M}$ & PComA & None & Clip + TCR & Complete & 5 & 5 & Unchanged & 168 \\
\hline 4 & $64 / F$ & PComA & Extrusion & Clip & Complete & 3 & 3 & Unchanged & 159 \\
\hline 5 & $3 / \mathrm{M}$ & MCA & Compaction & Clip + TCR & Complete & 4 & 5 & Improved & 150 \\
\hline 6 & $64 / M$ & PComA & Extrusion & Clip + PCR & Complete & 4 & 5 & Improved & 146 \\
\hline 7 & $33 / \mathrm{M}$ & MCA & Extrusion & Clip + TCR & Complete & 4 & 4 & Unchanged & 139 \\
\hline 8 & $16 / M$ & P2 PCA & Extrusion & Clip + TCR & Complete & 3 & 3 & Unchanged & 133 \\
\hline 9 & $42 / F$ & PComA & Extrusion & Clip & Complete & 4 & 4 & Unchanged & 128 \\
\hline 10 & $45 / F$ & ICA-OA & Compaction & Clip + TCR & Complete & 3 & 3 & Unchanged & 125 \\
\hline 11 & $46 / F$ & MCA & Extrusion & Clip & Complete & 5 & 5 & Unchanged & 120 \\
\hline 12 & $63 / F$ & PComA & Extrusion & Clip & Complete & 3 & 4 & Improved & 116 \\
\hline 13 & $49 / M$ & AComA & None & Clip + TCR & Complete & 5 & 5 & Unchanged & 110 \\
\hline 14 & $46 / M$ & AComA & Extrusion & Clip + PCR & Complete & 4 & 4 & Unchanged & 107 \\
\hline 15 & $34 / F$ & PComA & Compaction & Clip & Complete & 5 & 5 & Unchanged & 105 \\
\hline 16 & $55 / F$ & PComA & Extrusion & Clip & Complete & 5 & 5 & Unchanged & 99 \\
\hline 17 & $38 / \mathrm{M}$ & PComA & Extrusion & Clip + PCR & Complete & 5 & 5 & Unchanged & 95 \\
\hline 18 & $28 / F$ & A2 ACA & Extrusion & Clip & Complete & 5 & 4 & Worse & 92 \\
\hline 19 & $68 / F$ & PComA & Extrusion & Clip + PCR & Complete & 5 & 5 & Unchanged & 90 \\
\hline 20 & $60 / M$ & A3 ACA & Compaction & Clip + PCR & Complete & 3 & 3 & Unchanged & 84 \\
\hline 21 & $47 / F$ & ICA-OA & Compaction & Clip + TCR & Complete & 5 & 5 & Unchanged & 80 \\
\hline 22 & $53 / \mathrm{M}$ & AComA & Extrusion & Clip & Complete & 5 & 5 & Unchanged & 78 \\
\hline 23 & $68 / F$ & MCA & Extrusion & Clip + PCR & Complete & 3 & 2 & Worse & 75 \\
\hline 24 & $42 / \mathrm{M}$ & PComA & Extrusion & Clip + PCR & Complete & 4 & 3 & Worse & 70 \\
\hline 25 & $47 / F$ & AComA & Compaction & Clip + TCR & Complete & 5 & 5 & Unchanged & 68 \\
\hline 26 & $42 / \mathrm{M}$ & AComA & None & Clip + TCR & Complete & 5 & 5 & Unchanged & 67 \\
\hline 27 & $20 / \mathrm{M}$ & PComA & Compaction & Clip + TCR & Complete & 5 & 5 & Unchanged & 63 \\
\hline 28 & $16 / F$ & PComA & Extrusion & Clip & Complete & 4 & 5 & Improved & 60 \\
\hline 29 & $51 / \mathrm{M}$ & PComA & Extrusion & Clip & Complete & 5 & 5 & Unchanged & 60 \\
\hline 30 & $56 / F$ & AComA & Extrusion & Clip + TCR & Complete & 5 & 5 & Unchanged & 59 \\
\hline 31 & $57 / F$ & MCA & None & Clip + TCR & Complete & 5 & 5 & Unchanged & 55 \\
\hline 32 & $43 / M$ & AComA & Extrusion & Clip & Complete & 4 & 4 & Unchanged & 53 \\
\hline 33 & $54 / \mathrm{M}$ & AComA & Extrusion & Clip + PCR & Complete & 4 & 4 & Unchanged & 50 \\
\hline 34 & $52 / \mathrm{M}$ & MCA & None & Clip + TCR & Complete & 4 & 4 & Unchanged & 48 \\
\hline 35 & $48 / \mathrm{M}$ & A3 ACA & Extrusion & Clip + PCR & Complete & 3 & 4 & Improved & 47 \\
\hline 36 & $49 / \mathrm{M}$ & AComA & None & Clip & Complete & 5 & 4 & Worse & 43 \\
\hline 37 & $37 / M$ & MCA & Extrusion & Clip + PCR & Complete & 5 & 5 & Unchanged & 39 \\
\hline 38 & $45 / M$ & P2 PCA & Extrusion & Clip + PCR & Complete & 5 & 5 & Unchanged & 36 \\
\hline 39 & $47 / F$ & PComA & Extrusion & Clip & Complete & 4 & 4 & Unchanged & 32 \\
\hline 40 & $55 / F$ & PComA & Extrusion & Clip & Complete & 5 & 5 & Unchanged & 29 \\
\hline 41 & $45 / \mathrm{M}$ & AComA & Compaction & Clip + PCR & Complete & 5 & 5 & Unchanged & 28 \\
\hline 42 & $55 / \mathrm{M}$ & A2 ACA & Compaction & Clip + TCR & Complete & 5 & 5 & Unchanged & 23 \\
\hline 43 & $63 / F$ & PComA & Extrusion & Clip + PCR & Complete & 5 & 4 & Worse & 21 \\
\hline
\end{tabular}


Table 2 Microsurgical results and follow-up data (Continued)

\begin{tabular}{|c|c|c|c|c|c|c|c|c|c|}
\hline \multirow{2}{*}{$\begin{array}{l}\text { Patient } \\
\text { no. }\end{array}$} & \multirow{2}{*}{$\begin{array}{l}\text { Age } \\
(\mathrm{yr}) / \mathrm{sex}\end{array}$} & \multirow{2}{*}{$\begin{array}{l}\text { Aneurysm } \\
\text { location }\end{array}$} & \multirow{2}{*}{$\begin{array}{l}\text { Coil compaction } \\
\text { or extrusion }\end{array}$} & \multirow[t]{2}{*}{ Microsurgery } & \multirow{2}{*}{$\begin{array}{l}\text { Aneurysm } \\
\text { occlusion }\end{array}$} & \multicolumn{2}{|l|}{ GOS } & \multirow[t]{2}{*}{ Outcome } & \multirow{2}{*}{$\begin{array}{l}\text { Follow } \\
\text { up (m) }\end{array}$} \\
\hline & & & & & & Preop & Final & & \\
\hline 44 & $51 / \mathrm{M}$ & AComA & Compaction & Clip & Complete & 5 & 5 & Unchanged & 17 \\
\hline 45 & $59 / F$ & PComA & Extrusion & Clip + PCR & Complete & 5 & 5 & Unchanged & 14 \\
\hline 46 & $61 / F$ & PComA & Extrusion & Clip + TCR & Complete & 5 & 5 & Unchanged & 12 \\
\hline 47 & $62 / F$ & AComA & Extrusion & Clip + TCR & Complete & 4 & 5 & Improved & 12 \\
\hline 48 & $57 / M$ & A1 ACA & Compaction & Clip & Complete & 5 & 5 & Unchanged & 10 \\
\hline
\end{tabular}

yr years, $F$ female, $M$ male, $S A H$ subarachnoid hemorrhage, $M C A$ middle cerebral artery, $A C A$ anterior cerebral artery, $P C o m A$ posterior communicating artery, $P C A$ posterior cerebral artery, ICA-OA internal carotid artery-ophthalmic artery, AComA anterior communicating artery, $T C R$ total coil removal, $P C R$ partial coil removal, GOS Glasgow Outcome Scale, Preop preoperative, Final at the final follow-up

bypass surgery, and parent artery occlusion. In the past 17 years, a series of 48 consecutive patients with incomplete coiled or recurrent aneurysms were treated with microsurgical clipping. We presented our experience in treating this setting of aneurysms.

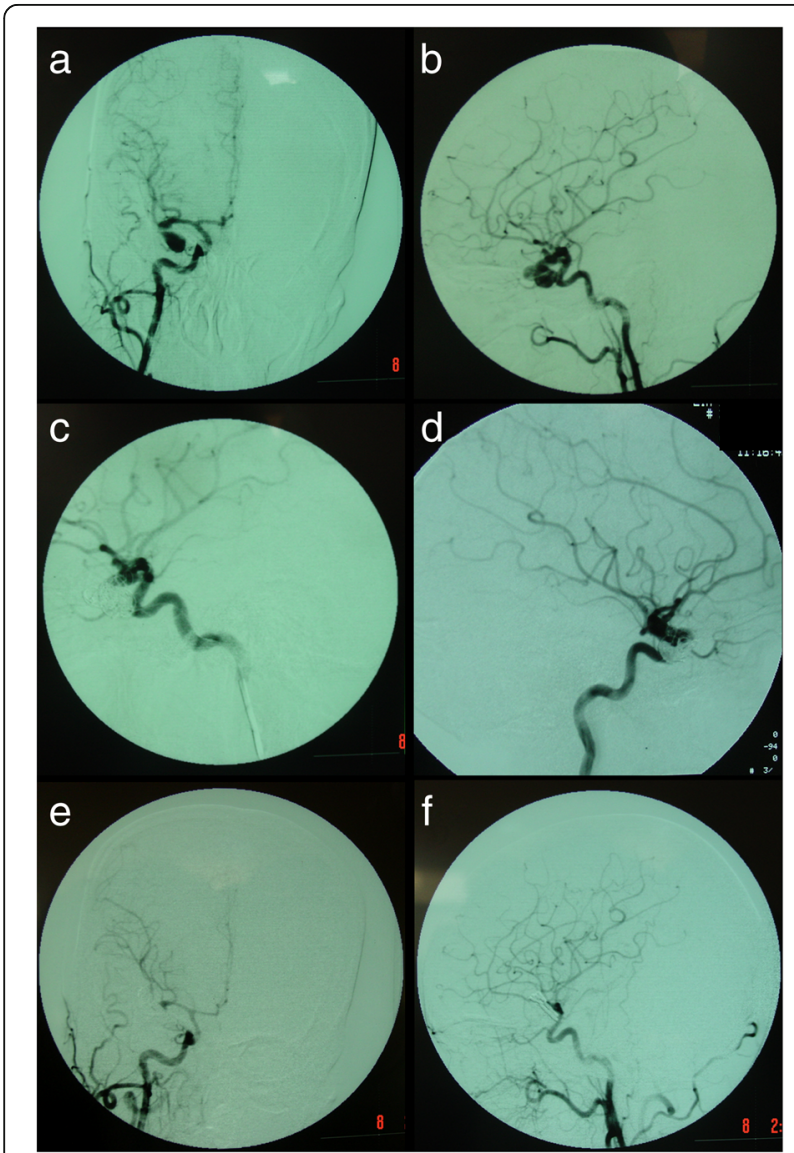

Fig. 1 Patient 1. A 47-year-old woman presented with a ruptured right MCA aneurysm (a, b). She was initially treated with endovascular coiling, and the aneurysm was completely obliterated (c). The follow-up DSA revealed an aneurysm recurrence 36 months after initial coil embolization (d). She was treated with microsurgical clipping and total coil removal. Postoperative DSA showed complete obliteration of the recurrent aneurysm $(\mathbf{e}, \mathbf{f})$

\section{Microsurgical technique}

Compared with those uncoiled aneurysms, previously coiled aneurysms cannot be softened, collapsed, or deflated easily [20,34]. Coiled aneurysms may become thrombotic and hardened, which may add difficulties to surgical procedure during the process of dissecting the aneurysm from surrounding structures. Coil migration into the aneurysm neck and parental or collateral arteries makes surgical

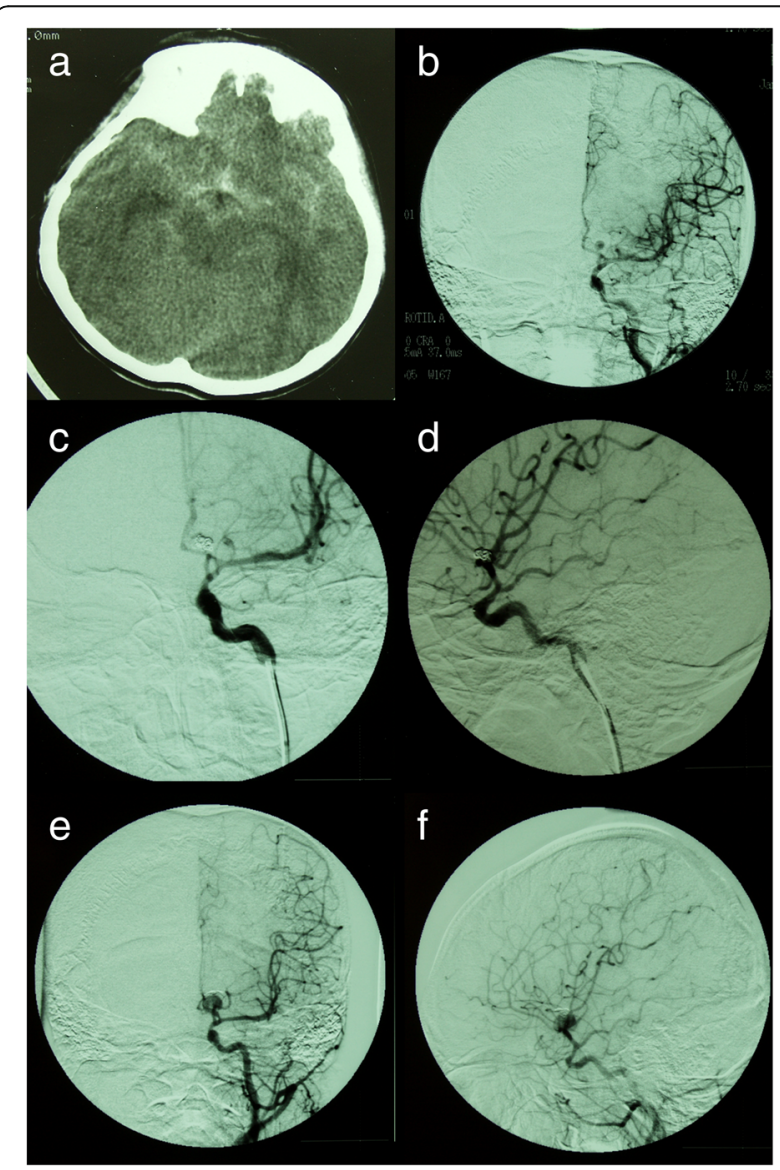

Fig. 2 Patient 2. A 12-year-old boy presented with a ruptured left ACA-A1 aneurysm $(\mathbf{a}, \mathbf{b})$. Complete obliteration was achieved after initial coiling $(\mathbf{c}, \mathbf{d})$. The follow-up DSA showed an aneurysm recurrence 3 months after initial coiling $(\mathbf{e}, \mathbf{f})$ 


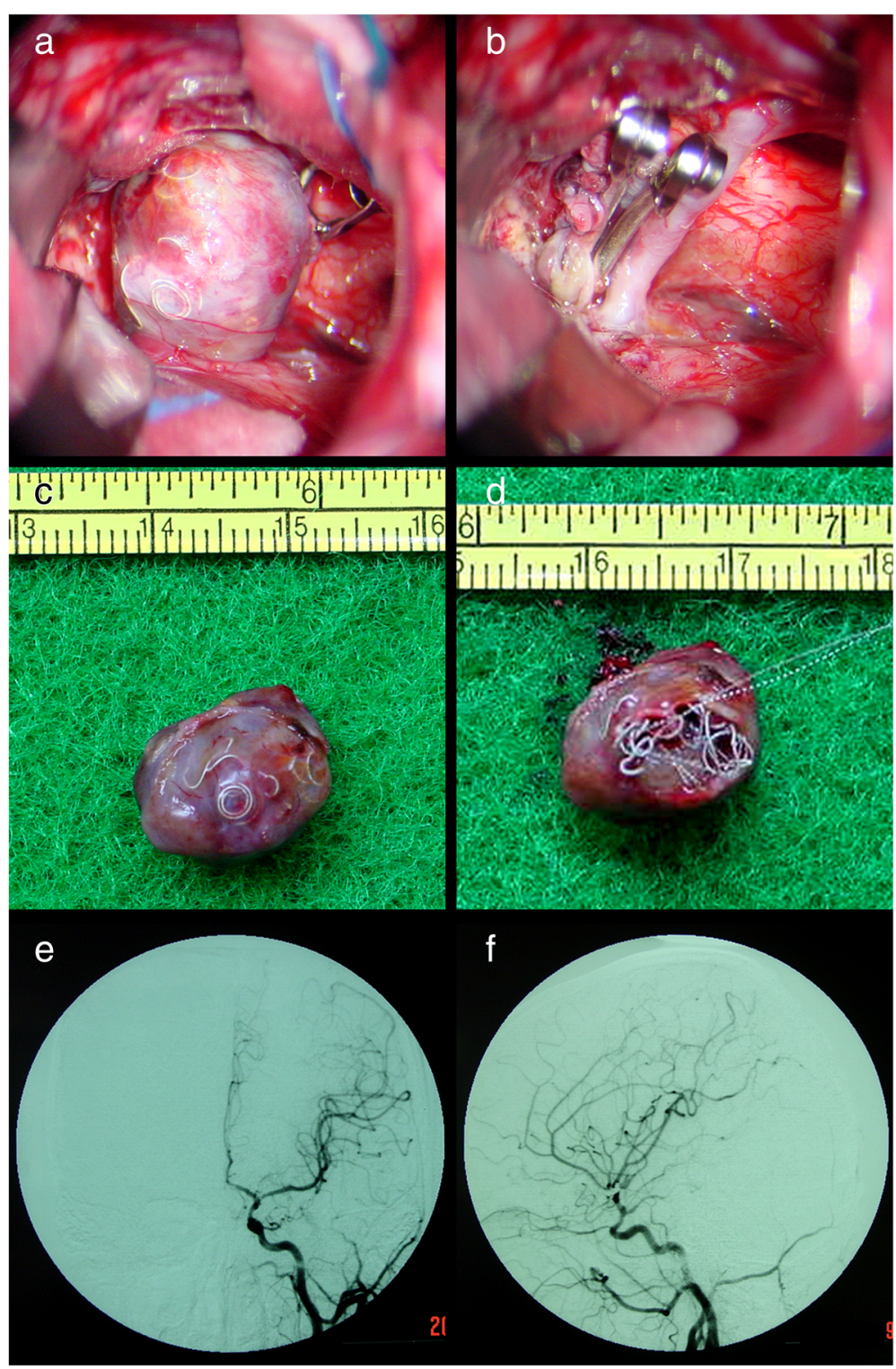

Fig. 3 Patient 2. Coil compaction was observed during surgery (a). The aneurysm was successfully clipped and the coiled mass was totally removed (b-d). Postoperative DSA revealed complete obliteration of the recurrent aneurysm $(\mathbf{e}, \mathbf{f})$

clipping more difficult. Coil extrusion into the subarachnoid space is also a challenging issue during dissection.

For the 6 patients with incompletely coiled aneurysms after initial embolization, the coiled aneurysms were easily dissected free from surrounding structures. All the 6 incompletely coiled aneurysms were clipped within 1 month after initial coiling when coils remain mobile, the thrombus is soft, and the coil mass was not compacted. We recommend early microsurgical intervention for incompletely coiled aneurysms to prevent aneurysm rupture. In our series, for the five incompletely coiled aneurysms with the size $>10 \mathrm{~mm}$, total coil removal was performed to prevent potential mass effects at a later stage after surgery. We do not recommend coil removal for those coiled aneurysms with the size $<10 \mathrm{~mm}$ unless the coils protrude into the neck or there is no adequate neck remnant for clipping.

In contrast to incompletely coiled aneurysms, recurrent aneurysms were often hard and less mobile. The thrombus sometimes makes it difficult to mobilize and clip these recurrent aneurysms. Coil compaction, migration, or extrusion adds difficulty for dissecting and clipping process. To achieve successful microsurgical clipping, we recommend obtaining early proximal control of the aneurysms.

\section{Coil extraction or not}

For the patients with coils migration into the aneurysm neck or the parental artery, it is necessary to remove the 


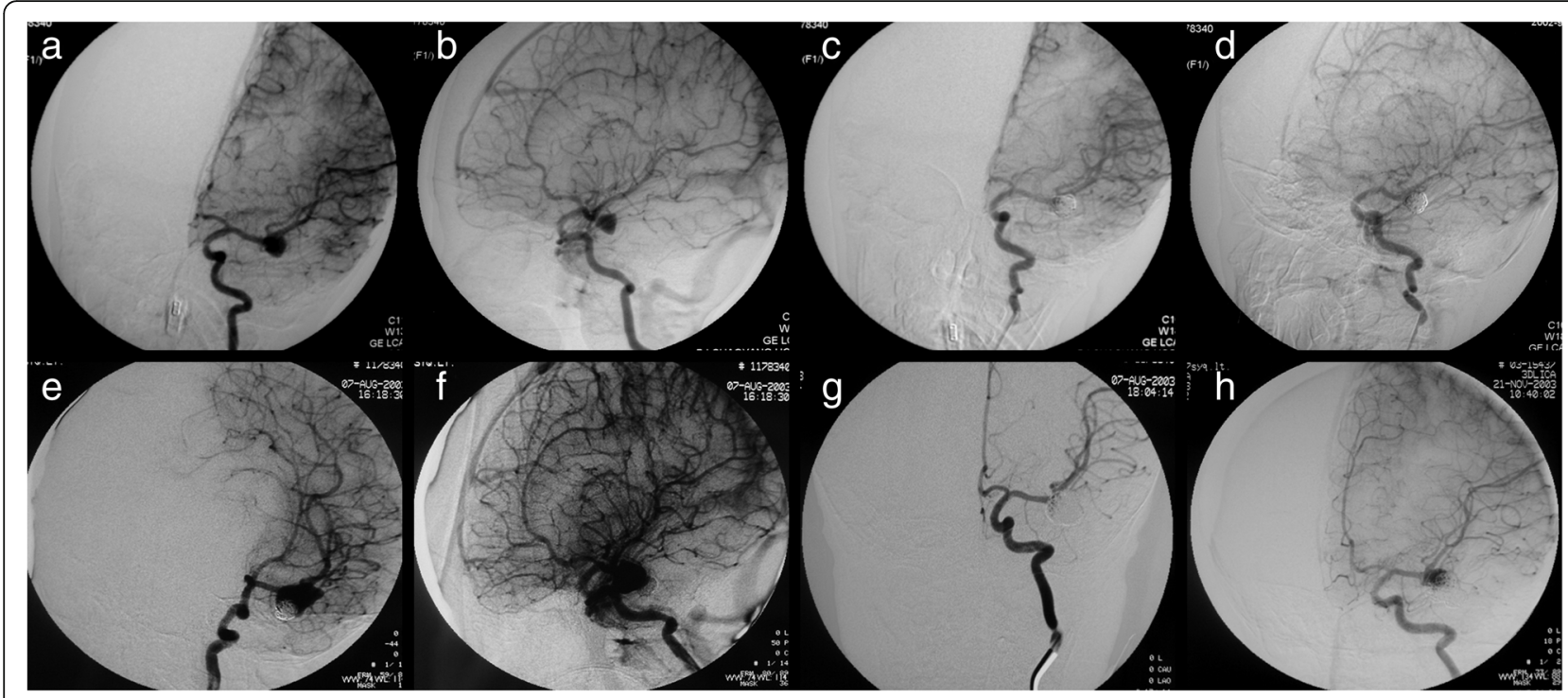

Fig. 4 Patient 5. A 3-year-old boy presented with an unruptured left MCA aneurysm (a, b). The aneurysm was completely obliterated after initial coiling (c, d). The follow-up DSA showed an aneurysm recurrence 11 months after initial coiling $(\mathbf{e}, \mathbf{f})$. At the same time, the recurrent aneurysm was completely obliterated with recoiling $(\mathbf{g})$. Three and a half months after recoiling, follow-up DSA showed a second recurrence of the coiled aneurysm (h)

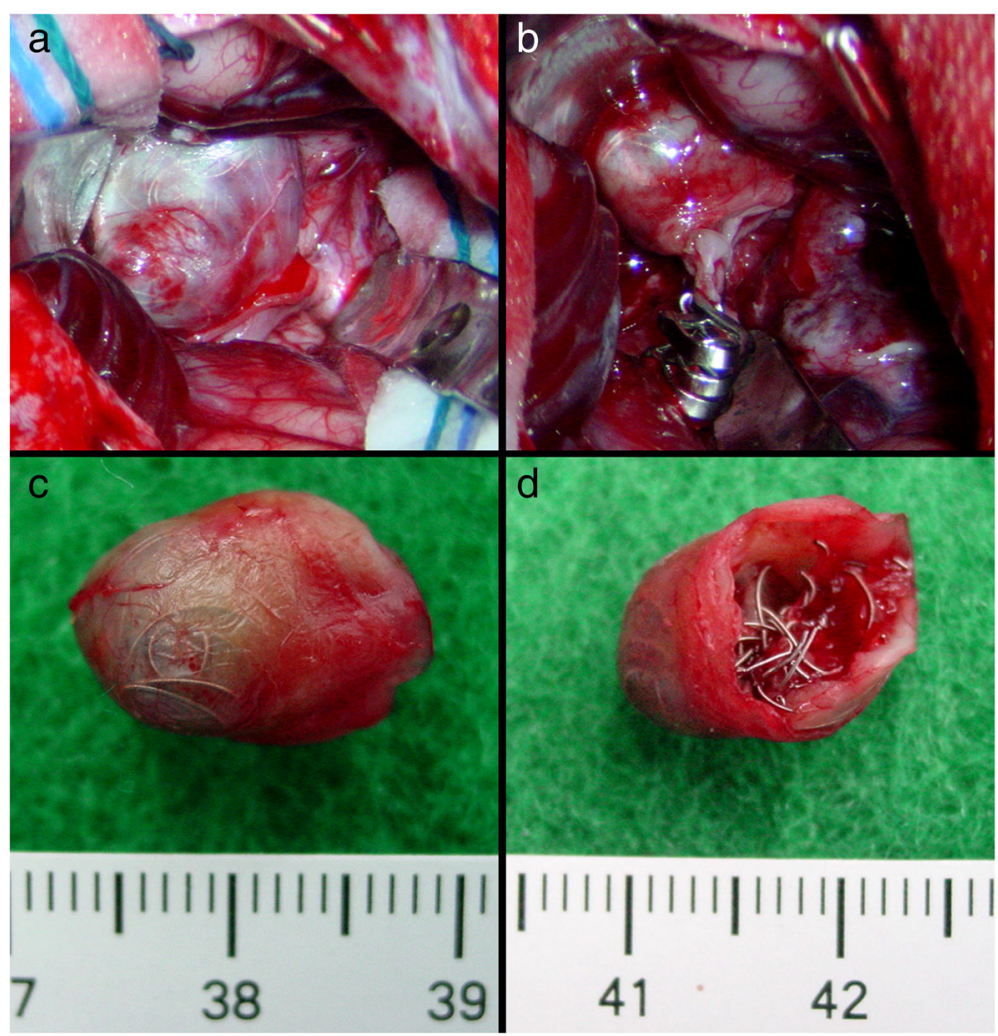

Fig. 5 Patient 5. Coil compaction was observed during surgery (a). The aneurysm was successfully occluded and the coiled mass was totally removed (b-d) 

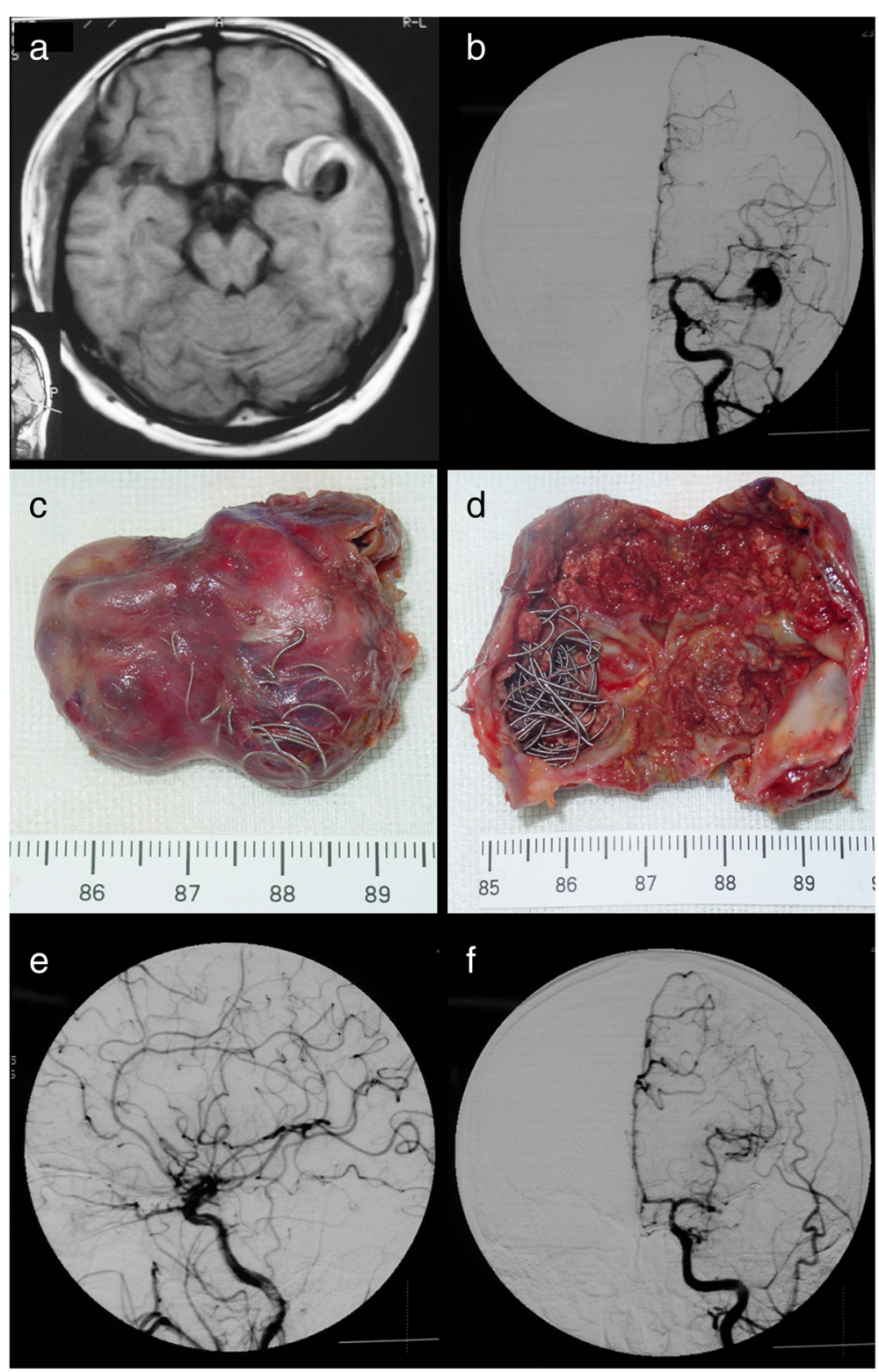

Fig. 6 Patient 7. A 33-year-old man presented with a recurrent aneurysm 15 months after initial coiling $(\mathbf{a}, \mathbf{b})$. The coiled mass was completely removed $(\mathbf{c}, \mathbf{d})$. Coil extrusion through the aneurysm wall $(\mathbf{c})$ and coil compaction (d) can be seen. Postoperative follow-up DSA showed complete obliteration of the recurrent aneurysm $(\mathbf{e}, \mathbf{f})$

coils to get enough space to clip the aneurysm neck. For patients with coiled aneurysms that caused mass effects, partial or total coil removal should be performed. Partial or total coil removal can provide adequate decompression of the aneurysm sac, relieve the mass effect caused by coiled mass, and help to achieve successful neck clipping.

Removal of coils from coiled aneurysms is technically challenging. Controversies exist regarding the danger and necessity of coil extraction during surgery $[6,12,22,26$, $28,29,34]$. In our series, microsurgical clipping with partial or complete coil removal was performed in 67\% (32/
48) of the patients. In the literature review of 375 incompletely coiled or recurrent aneurysms, only $13 \%$ of coils were extracted and most underwent direct microsurgical clipping without coil removal [2]. Some authors recommend systematic extraction of coils to achieve successful clipping, even if the coils have protruded into the aneurysm neck or parent arteries [22, 28, 31]. While other authors emphasize the danger of removing coils from previously coiled aneurysms [10, 12, 29]. Horowitz et al. initially planned to perform coil extraction as a goal in all cases, but only achieved in $40 \%$ of reported cases. As a result, they favored direct clipping whenever possible to 


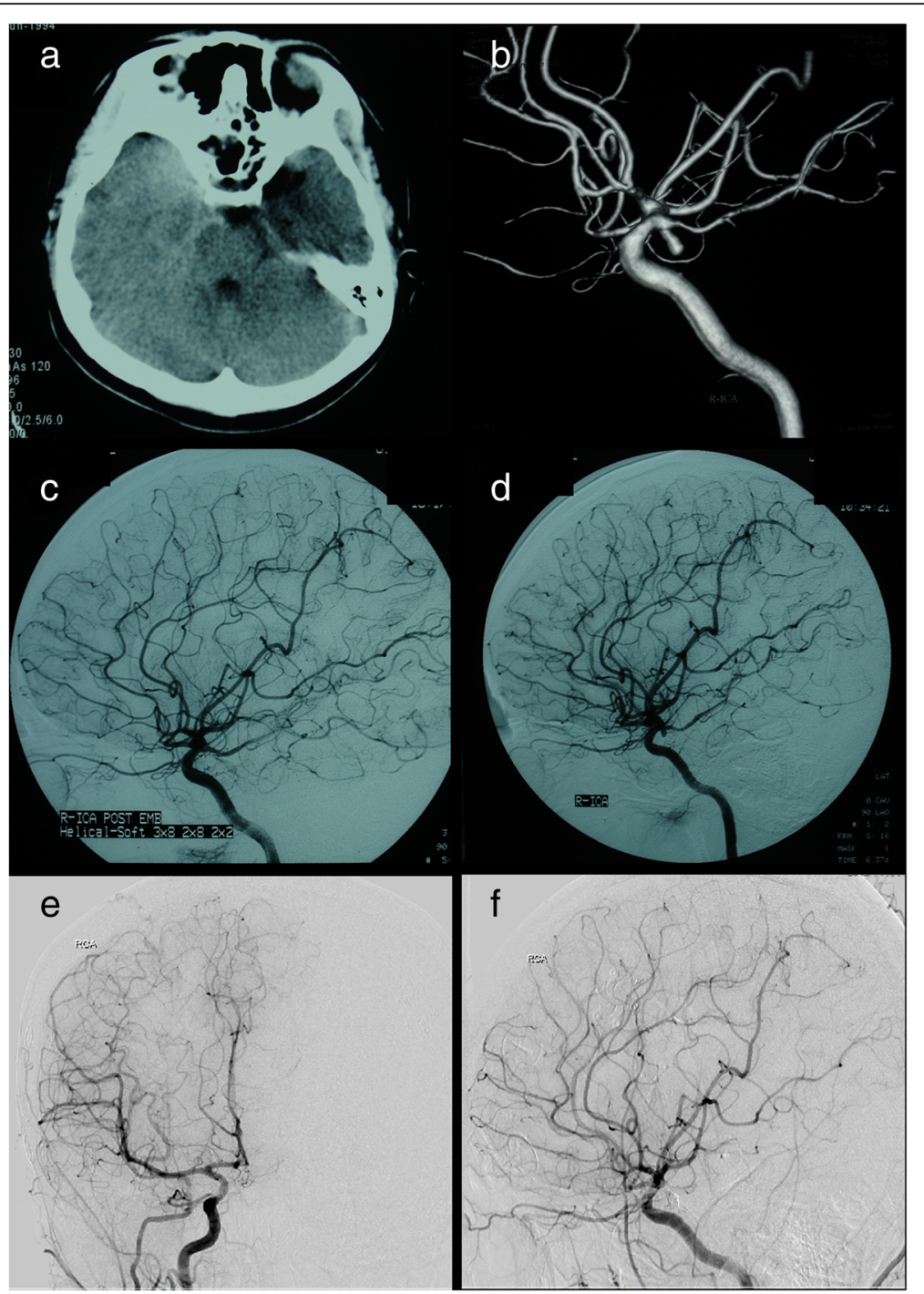

Fig. 7 Patient 28. A 16-year-old woman presented with a ruptured right posterior communicating artery aneurysm (a, b). The aneurysm was completely obliterated with initial coiling (c). The follow-up DSA showed aneurysm recurrence 12 months after initial coiling (d). Microsurgical clipping without coil removal and postoperative DSA showed complete obliteration of the recurrent aneurysm $(\mathbf{e}, \mathbf{f})$

avoid damage to the parent artery $[2,15]$. Thornton et al. performed coil extraction in $81 \%$ in their series [31]. In fact, most (64\%) of their cases underwent microsurgical management within 2 weeks after endovascular coiling. Coil extraction is relatively easier if the coils are placed "recently" [31]. In our series, all the six patients with incompletely coiled aneurysms underwent surgical clipping within 1 month after coiling and total coil extraction was achieved in five patients (83.3\%). Dorfer reported a patient with recurrent aneurysm 4 years after embolization. The coil removal was attempted and resulted in aneurysm rupture at the neck, leading to sacrificing the ICA and permanent morbidity [12]. In our series, we tried to remove the coiled mass when it prevents satisfactory clipping of the aneurysm. In such situations as coil-caused immobilization, no adequate neck for clipping, coil protrusion into the neck or parental arteries, coil-induced mass effects and potential mass effects, the coiled mass inside the aneurysm has to be removed to appropriately apply clips and achieve favorable outcomes. According to the literature and our experience, if coil removal is deemed necessary but cannot be done safely, partial coil removal is recommended to facilitate clipping [2]. As a result, partial coil removal to achieve proper clip placement or decompress mass effect was done in $29.2 \%$ (14/48) of our cases. Alternatively, to facilitate surgical clipping, some authors recommend simple opening of the aneurysm dome to extrude the coils partially (without coil removal) $[1,2,11,20$, $33,35,36]$. As to the literature and our experience, if coil removal is attempted, it is essential to achieve early control 


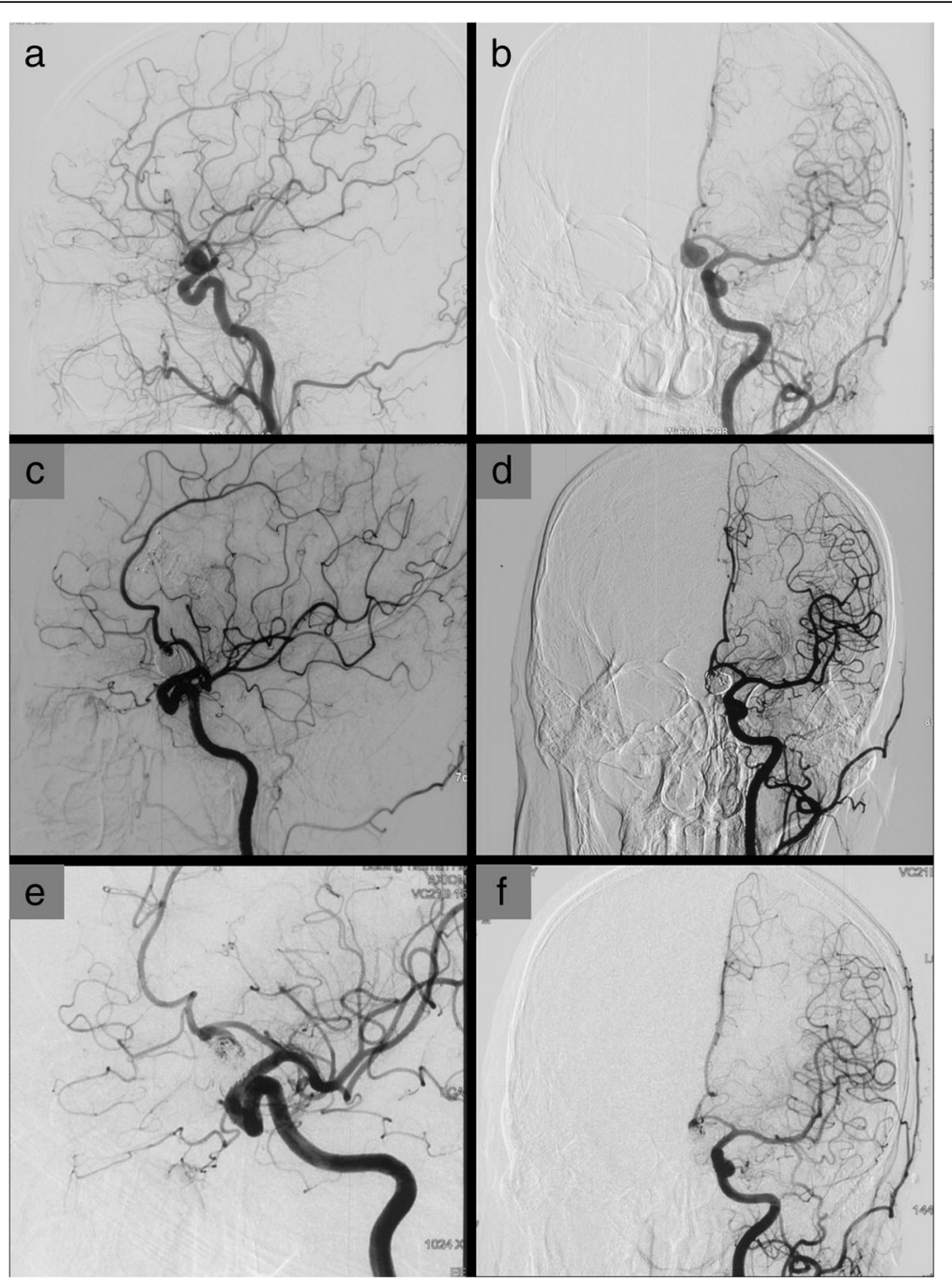

Fig. 8 Patient 47. A 62-year-old woman presented with an unruptured AcomA aneurysm (a, b). Complete obliteration was achieved after initial coiling $(\mathbf{c}, \mathbf{d})$. The patient experienced visual failure 9 months after initial coiling and DSA showed an aneurysm recurrence $(\mathbf{e}, \mathbf{f})$

of the proximal afferent and distal efferent vessels. Vigorous traction should be avoided during dissection to reduce the risk of aneurysm sac separation from the parental artery $[24,31,32]$.

Aneurysm location is also a factor that influences coil removal and surgical clipping. Regarding our experience, most of the incompletely coiled and recurrent aneurysms were located in the anterior circulation and only two were located in the P2 segment of PCA. The locations such as ACA, AcomA MCA, and PcomA provided easier access and enough space for aneurysm dissection, coil removal, and surgical clipping in most cases. For the two patients with coiled aneurysms in the P2 segment of the PCA, the coiled mass was totally removed in one patient and partially removed in the other patient. None of the coiled aneurysms in our series were located in such confining anatomic locations as the basilar trunk, basilar apex, or carotid bifurcation [3, 4, 19]. For coiled aneurysms in such locations, surgical clipping is extremely challenging. Recoiling may be the preferred choice.

Aneurysm size is also a factor that influences the coil removal and surgical clipping in our series. In our experience, for small-sized $(<10 \mathrm{~mm})$ coiled aneurysms, if they have adequate neck for clipping, without coils in the neck or mass effects, we recommend direct surgical clipping without coil removal. If they have coils in the neck, or mass effects, or no adequate neck remnant for clipping, partial or total coil removal should be performed to achieve successful surgical clipping. For those coiled aneurysms with the size $>10 \mathrm{~mm}$, we recommend partial or total coil removal to facilitate surgical clipping, relieve mass effects, or prevent potential postsurgical mass effects. However, all the clipping procedures should not be performed at the expense of patients' safety.

In our series, for aneurysms with coil protrusion into the neck or no adequate neck for clipping, we had to 


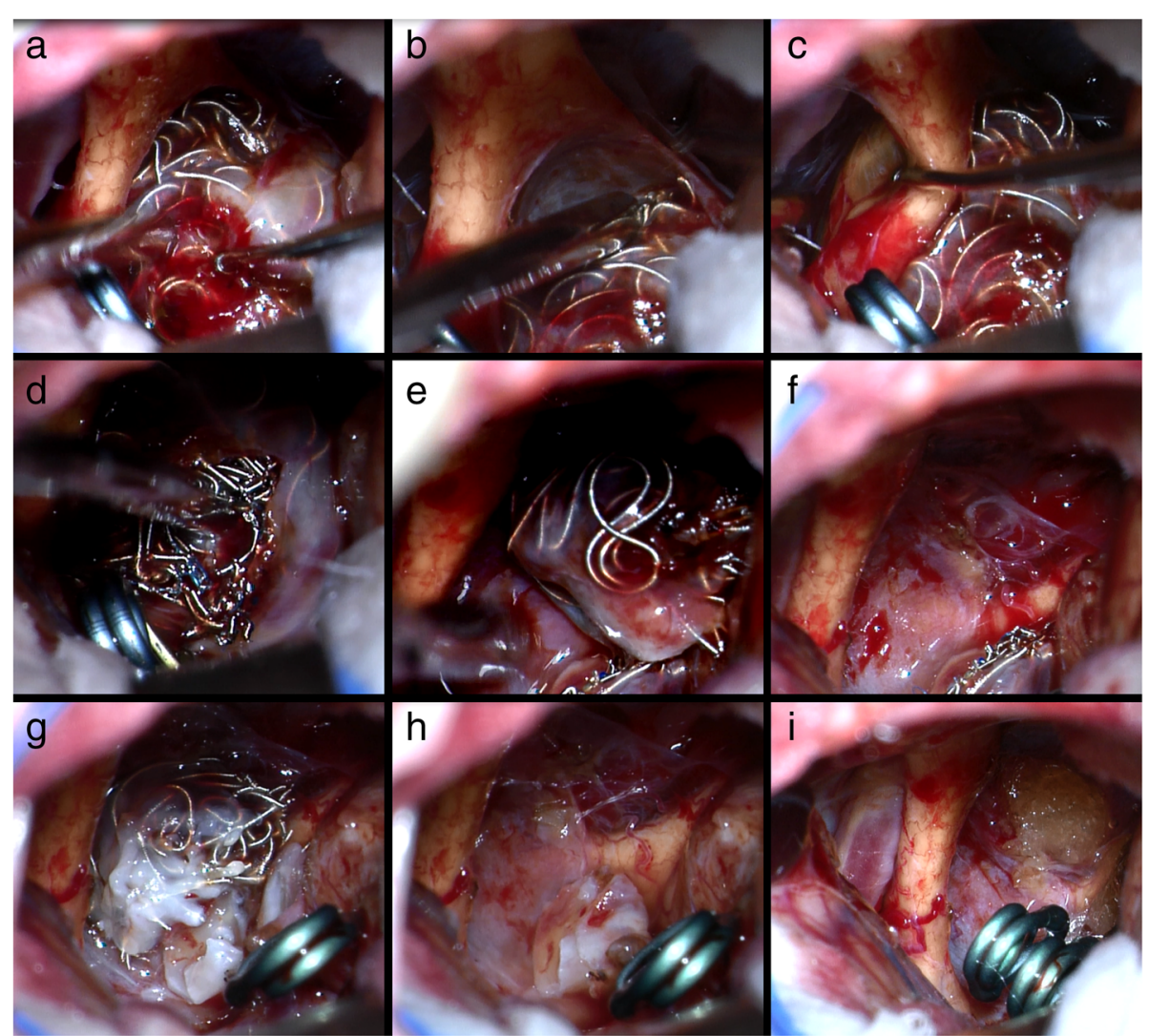

Fig. 9 Intraoperative results of patient 47. Coil extrusion can be observed during surgery (a-c). The optic chiasm was severely compressed by the coiled mass $(\mathbf{a}-\mathbf{c})$. After exposure and control of the proximal and distal vessels of the aneurysm, careful dissection was performed to free the coiled mass from surrounding structures. The coiled mass was transected $(\mathbf{d}, \mathbf{e})$ and half of the coiled mass was removed. (f) The residual half of coiled mass become more mobile and there was adequate neck for clipping. After clipping with one clip, the residual half of coiled mass was removed $(\mathbf{g}, \mathbf{h})$. Another clip was placed next to the first clip (i)

remove partial or total coiled mass to achieve complete occlusion of the aneurysms or prevent parent artery stenosis. Izumo reported a combination using of a fenestrated clip and a second type of clip in four of six patients to successfully occlude the recurrent aneurysms with coils in the neck, and no patients needed coil removal [16]. This technique is reasonable in treating recurrent aneurysms. However, in the practice of treating coiled or recurrent aneurysms, there are times when coil removal is unavoidable. Considering the difficulty of coil removal and the potential complications of surgical clipping created by the presence of coils in the aneurysm neck, some authors recommend observation for these aneurysms with coils in the neck until additional coil compaction facilitates clipping $[2,11,14,20,31]$. We agree with their recommendations. However, these patients should be followed clinically and angiographically with close observation.

\section{Surgical outcomes}

In the literature review, the mean obliteration rate after microsurgical clipping of incompletely coiled or recurrent aneurysms was $93 \%$ and $42 \%$ of the authors reported $100 \%$ obliteration [2]. A mean postsurgical GOS of 4.4 was achieved and most cases experienced an unchanged postsurgical GOS score compared with their preoperative state [2]. In our series, the obliteration rate was $100 \%$. The mean GOS at the final follow-up was 4.5 , and $90 \%$ had an unchanged or improved GOS after surgical clipping. The outcome data in the literature and our study showed that microsurgical clipping of incompletely coiled or recurrent aneurysms can achieve high obliteration rate and favorable clinical outcomes with low morbidity and mortality in selected patients.

\section{Limitations}

We retrospectively reviewed our 17-year experience of treating previously coiled or recurrent aneurysms. Our series represent a highly selected group of patients who sought for microsurgical clipping of their coiled or recurrent aneurysms after initial endovascular coiling. Although successful microsurgical clipping was achieved in all the patients, the aneurysms in our series were relatively easily accessible. We must admit that more complex aneurysms with high surgical difficulties should be managed with recoiling, bypass surgery, trapping, or wrapping. 


\section{Conclusions}

Microsurgical clipping is effective for incompletely coiled or recurrent aneurysms after initial coiling. For recurrent aneurysms with coils in the neck, inadequate neck for clipping or mass effects on surrounding structures, partial coil removal, or total removal of the coil mass can facilitate surgical clipping and successful obliteration of the aneurysms. However, coil extraction is challenging and should be decided and performed cautiously by experienced vascular neurosurgeons.

\section{Abbreviations}

CARAT: Cerebral aneurysm rerupture after treatment; DSA: Digital subtraction angiography; ISAT: International subarachnoid aneurysm trial; MRA: Magnetic resonance angiography

\section{Acknowledgements}

We thank our sponsors (the National Natural Science Foundation of China and Key Project of Beijing Municipal Science \& Technology Commission) for their financial support.

\section{Funding}

This study was funded by the National Natural Science Foundation of China (Grant No. 81471210) and Key Project of Beijing Municipal Science \& Technology Commission (Grant No. D161100003816004). The sponsors had no role in the design or conduct of this research.

\section{Availability of data and materials}

Data sharing not applicable to this article as no datasets were generated or analyzed during the current study.

\section{Authors' contributions}

Author contributions to the study and manuscript preparation include the following. All authors contributed to the conception and design. XT, JW, and $\mathrm{QL}$ contributed to the acquisition of data. XT, JW, and QL contributed to the analysis and interpretation of data. XT contributed to the drafting of the article. All authors contributed to the critically revision of the article. All authors contributed to the reviewing of the submitted version of the manuscript. SW approved the final version of the manuscript on behalf of all authors. JW contributed to the statistical analysis. SW contributed to the administrative/ technical/material support. SW contributed to the study supervision.

\section{Ethics approval and consent to participate}

This study was approved by the Institutional Review Board of Beijing Tiantan Hospital, Capital Medical University. All procedures performed in this study were in accordance with the ethical standards of the institutional research committee and with the 1964 Helsinki declaration and its later amendments or comparable ethical standards. For this type of study formal consent is not required.

\section{Consent for publication}

Written informed consents were obtained from all participants or their legally authorized representatives and privacy of patients was effectively protected.

\section{Competing interests}

All authors certify that we have no affiliations with or involvement in any organization or entity with any financial interest (such as honoraria; educational grants; participation in speakers' bureaus; membership, employment, consultancies, stock ownership, or other equity interest; and expert testimony or patent-licensing arrangements) or non-financial interest (such as personal or professional relationships, affiliations, knowledge, or beliefs) in the subject matter or materials discussed in this manuscript.

\section{Author details}

${ }^{1}$ Department of Neurosurgery, Beijing Tiantan Hospital, Capital Medical University, Beijing 100050, China. ${ }^{2}$ China National Clinical Research Center for Neurological Diseases, Beijing, China. ${ }^{3}$ Center of Stroke, Beijing Institute for Brain Disorders, Beijing, China. ${ }^{4}$ Beijing Key Laboratory of Translational Medicine for Cerebrovascular Diseases, Beijing, People's Republic of China.
${ }^{5}$ Department of Neurosurgery, Xuanwu Hospital, Capital Medical University, Beijing, China.

Received: 30 October 2018 Accepted: 30 January 2019

Published online: 07 March 2019

\section{References}

1. Aoun SG, Rahme RJ, El Ahmadieh TY, Bendok BR, Hunt Batjer H. Incorporation of extruded coils into the third nerve in association with third nerve palsy. J Clin Neurosci. 2013;20:1299-302.

2. Arnaout OM, El Ahmadieh TY, Zammar SG, El Tecle NE, Hamade YJ, Aoun RJ, Aoun SG, Rahme RJ, Eddleman CS, Barrow DL, Batjer HH, Bendok BR. Microsurgical treatment of previously coiled intracranial aneurysms: systematic review of the literature. World Neurosurg. 2015;84:246-53.

3. Asgari S, Doerfler A, Wanke I, Schoch B, Forsting M, Stolke D. Complementary management of partially occluded aneurysms by using surgical or endovascular therapy. J Neurosurg. 2002;97:843-50.

4. Boet R, Poon WS, Yu SC. The management of residual and recurrent intracranial aneurysms after previous endovascular or surgical treatment-a report of eighteen cases. Acta Neurochir. 2001;143:1093-101.

5. Campi A, Ramzi N, Molyneux AJ, Summers PE, Kerr RS, Sneade M, Yarnold JA, Rischmiller J, Byrne JV. Retreatment of ruptured cerebral aneurysms in patients randomized by coiling or clipping in the International Subarachnoid Aneurysm Trial (ISAT). Stroke. 2007:38:1538-44.

6. Chung J, Lim YC, Kim BS, Lee D, Lee KS, Shin YS. Early and late microsurgical clipping for initially coiled intracranial aneurysms. Neuroradiology. 2010;52:1143-51.

7. Civit T, Auque J. Delayed aneurysm regrowth. J Neurosurg. 1999:90:807-9.

8. Civit T, Auque J, Marchal JC, Bracard S, Picard L, Hepner H. Aneurysm clipping after endovascular treatment with coils: a report of eight patients. Neurosurgery. 1996;38:955-60.

9. Cowan JA Jr, Ziewacz J, Dimick JB, Upchurch GR Jr, Thompson BG. Use of endovascular coil embolization and surgical clip occlusion for cerebral artery aneurysms. J Neurosurg. 2007;107:530-5

10. Davies JM, Lawton MT. Advances in open microsurgery for cerebral aneurysms. Neurosurgery. 2014;74(Suppl 1):S7-16.

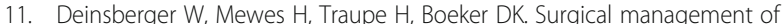
previously coiled intracranial aneurysms. Br J Neurosurg. 2003;17:149-54.

12. Dorfer C, Gruber A, Standhardt H, Bavinzski G, Knosp E. Management of residual and recurrent aneurysms after initial endovascular treatment. Neurosurgery. 2012;70:537-53.

13. Guglielmi G, Viñuela F, Duckwiler G, Dion J, Lylyk P, Berenstein A, Strother C, Graves V, Halbach V, Nichols D, Hopkins LN, Ferguson R, Sepetka I. Endovascular treatment of posterior circulation aneurysms by electrothrombosis using electrically detachable coils. J Neurosurg. 1992;77: $515-24$

14. Gurian JH, Martin NA, King WA, Duckwiler GR, Guglielmi G, Vinuela F. Neurosurgical management of cerebral aneurysms following unsuccessful or incomplete endovascular embolization. J Neurosurg. 1995;83:843-53.

15. Horowitz M, Purdy P, Kopitnik T, Dutton K, Samson D. Aneurysm retreatment after Guglielmi detachable coil and nondetachable coil embolization: report of nine cases and review of the literature. Neurosurgery. 1999:44:712-9 discussion 719-720.

16. Izumo T, Matsuo T, Morofuji Y, Hiu T, Horie N, Hayashi K, Nagata I. Microsurgical clipping for recurrent aneurysms after initial endovascular coil embolization. World Neurosurg. 2015;83:211-8.

17. Johnston SC, Dowd CF, Higashida RT, Lawton MT, Duckwiler GR, Gress DR, CARAT Investigators. Predictors of rehemorrhage after treatment of ruptured intracranial aneurysms: the Cerebral Aneurysm Rerupture After Treatment (CARAT) study. Stroke. 2008;39:120-5.

18. Johnston SC, Dowd CF, Lawton MT, CARAT Investigators, et al. Rates of delayed rebleeding from intracranial aneurysms are low after surgical and endovascular treatment. Stroke. 2006;37:1437-42.

19. Lawton MT, Quinones-Hinojosa A, Sanai N, Malek JY, Dowd CF. Combined microsurgical and endovascular management of complex intracranial aneurysms. Neurosurgery. 2008;62:1503-15.

20. Lejeune JP, Thines $L$, Taschner $C$, Bourgeois $P$, Henon $H$, Leclerc $X$ Neurosurgical treatment for aneurysm remnants or recurrences after coil occlusion. Neurosurgery. 2008;63:684-91.

21. Molyneux AJ, Kerr RS, Yu LM, Clarke M, Sneade M, Yarnold JA, Sandercock P, International Subarachnoid Aneurysm Trial (ISAT) Collaborative Group. 
International Subarachnoid Aneurysm Trial (ISAT) of neurosurgical clipping versus endovascular coiling in 2143 patients with ruptured intracranial aneurysms: a randomized comparison of effects on survival, dependency, seizures, rebleeding, subgroups, and aneurysm occlusion. Lancet. 2005;366:809-17.

22. Nakamura M, Montibeller GR, Götz F, Krauss JK. Microsurgical clipping of previously coiled intracranial aneurysms. Clin Neurol Neurosurg. 2013;115: 1343-9.

23. Park HK, Horowitz M, Jungreis C, Genevro J, Koebbe C, Levy E, Kassam A. Periprocedural morbidity and mortality associated with endovascular treatment of intracranial aneurysms. AJNR Am J Neuroradiol. 2005;26:506-14.

24. Pillai P, Karim A, Nanda A. Technical challenges to surgical clipping of aneurysmal regrowth with coil herniation following endovascular treatment—a case report. J Med Case Rep. 2007;1:168

25. Renowden SA, Koumellis P, Benes V, Mukonoweshuro W, Molyneux AJ, McConachie NS. Retreatment of previously embolized cerebral aneurysms: the risk of further coil embolization does not negate the advantage of the initial embolization. AJNR Am J Neuroradiol. 2008;29:1401-4.

26. Romani R, Lehto H, Laakso A, Horcajadas A, Kivisaari R, Fraunberg M, Niemelä M, Rinne J, Hernesniemi J. Microsurgical technique for previously coiled aneurysms. J Neurosurg Sci. 2011;55:139-50.

27. Romani R, Lehto H, Laakso A, Horcajadas A, Kivisaari R, von und zu Fraunberg M, Niemelä M, Rinne J, Hernesniemi J. Microsurgery for previously coiled aneurysms: experience with 81 patients. Neurosurgery. 2011:68:140-53 discussion 153-154

28. Rubino PA, Castro JM, Kitroser M, Bottan JS, Salas E, Lambre J, Chiarullo M, Bustamante J. Microsurgical clipping of previously coiled aneurysms. World Neurosurg. 2013;82:e203-8.

29. Sanai N, Caldwell N, Englot DJ, Lawton MT. Advanced technical skills are required for microsurgical clipping of posterior communicating artery aneurysms in the endovascular era. Neurosurgery. 2012;71:285-94.

30. Serbinenko FA. Balloon catheterization and occlusion of major cerebral vessels. J Neurosurg. 1974;41:125-45.

31. Thornton J, Dovey Z, Alazzaz A, Misra M, Aleti'ch VA, Debrun GM, Ausman $\mathrm{Jl}$, Charbel FT. Surgery following endovascular coiling of intracranial aneurysms. Surg Neurol. 2000;54:352-60.

32. Tirakotai W, Sure U, Yin Y, Benes L, Schulte DM, Bien S, Bertalanffy H. Surgery of intracranial aneurysms previously treated endovascularly. Clin Neurol Neurosurg. 2007;109:744-52.

33. Veznedaroglu E, Benitez RP, Rosenwasser RH. Surgically treated aneurysms previously coiled: lessons learned. Neurosurgery. 2008;62:1516-24.

34. Waldron JS, Halbach W, Lawton MT. Microsurgical management of incompletely coiled and recurrent aneurysms: trends, techniques, and observations on coil extrusion. Neurosurgery. 2009;64:301-15 discussion 315-317.

35. Yoshida K, Wataya T, Hojo M, Doi D, Yamagata S. Surgical clipping of a recurrent small saccular aneurysm after repeated coil embolization. Neurol Med Chir (Tokyo). 2005:45:356-9.

36. Zhang YJ, Barrow DL, Cawley CM, Dion JE. Neurosurgical management of intracranial aneurysms previously treated with endovascular therapy. Neurosurgery. 2003:52:283-93 discussion 293-295.

Ready to submit your research? Choose BMC and benefit from:

- fast, convenient online submission

- thorough peer review by experienced researchers in your field

- rapid publication on acceptance

- support for research data, including large and complex data types

- gold Open Access which fosters wider collaboration and increased citations

- maximum visibility for your research: over $100 \mathrm{M}$ website views per year

At $\mathrm{BMC}$, research is always in progress.

Learn more biomedcentral.com/submissions 